\title{
Experiencias de mujeres víctimas denunciantes de violencia ante el sistema jurídico colombiano
}

\author{
Experiences of women victims of violence reporting to the \\ colombian legal system
}

Nicolasa María Durán Palacio*

Sara Catalina Posada Marín**

\section{Resumen}

Este artículo de investigación ${ }^{1}$ presenta el análisis de las experiencias de denuncia de las mujeres víctimas de violencia intrafamiliar en la utilización del sistema jurídico colombiano. Mediante un diseño cualitativo fenomenológico, método narrativo testimonial, apoyado con entrevistas a -profundidad, se obtuvo el develamiento de los significados de las experiencias de mujeres denunciantes, víctimas de violencia en sus relaciones de pareja, cuando acuden en búsqueda de protección y garantía de derechos en el sistema jurídico colombiano. Del análisis narrativo, surgieron cuatro categorías: decisión de denunciar por intensificación de la violencia de pareja, experiencia de denuncia ante las autoridades, desconfianza en el sistema jurídico y consecuencias negativas para las mujeres víctimas denunciantes de maltrato intrafamiliar. Se concluye que las mujeres denunciantes, no solo atraviesan por un proceso complejo para romper con el ciclo de agresiones en sus relaciones de pareja, sino que además padecen violencia institucional en un sistema jurídico hostil, poco empático, que las re-victimiza y es incapaz de proteger su vida y sus derechos.

Palabras claves: Violencia doméstica, violación de los derechos humanos, estereotipo sexual, administración de justicia, justicia social.

\footnotetext{
Abstract

This research article presents the experiences of women victims of domestic violence in using the Colombian legal system. By means of a qualitative phenomenological design, a

* Doctora en Filosofía. Magíster en Psicología. Psicóloga. Docente Investigadora Universidad Católica Luis Amigó. Correo: nicolasa.duranpa@amigo.edu.com

** Magíster en Intervenciones Psicosociales. Psicóloga. Correo: saraposadam@gmail.com

${ }^{1}$ Este artículo surgió de la investigación Violencia de género institucionalizada en el sistema jurídico colombiano. Realizada al interior de la línea de investigación "problemáticas psicosociales contemporáneas" en el marco de la Maestría en Intervenciones Psicosociales de la Universidad Católica Luis Amigó de Medellín, Colombia.
} 
testimonial narrative method, supported by in-depth interviews, it was obtained the unveiling of the meanings of the experiences of denouncing women, victims of violence in their couple relationships, when they come in search of protection and guarantee of rights in the Colombian legal system. From the narrative analysis, four categories emerged: decision to denounce due to the intensification of the violence of couple, experience of reporting to the authorities, distrust in the legal system and negative consequences for the women victims of domestic abuse. It is concluded that women who report not only go through a complex process to break the cycle of aggressions in their couple relationships, but also suffer institutional violence in a hostile, not very empathetic legal system that revictimizes them and is incapable of protecting their lives and rights.

Keywords: Domestic violence, human rights violations, sexual stereotype, administration of justice, social justice.

Fecha de recepción: Abril 2021

Fecha de aprobación: Diciembre 2021

\section{Introducción}

La violencia contra las mujeres es un fenómeno complejo, estructural e histórico, que se define y caracteriza por una serie de actos, conductas que causan muerte, daño o sufrimiento, físico o psicológico a la mujer, basada en su género y que ocurre tanto en los espacios privados como públicos, así se define en la Convención Belem do Pará (Organización de los Estados Americanos -OEA-, 1994). Si bien esta definición proporciona una mirada amplia y evidencia diferentes tipos de violencias, e incluye los ámbitos en donde ocurren los hechos, existen otras formas coercitivas, inseparables de las dinámicas tradicionales del orden jerárquico del género, donde las relaciones de poder se presentan de manera sutil, estereotipada y se dispersan en la cotidianidad; y en tanto hacen parte de un juego lingüístico y una jerga de nominaciones no estandarizadas, se convierte en un fenómeno manipulable, que se naturaliza en lo doméstico y en las diferentes organizaciones, instituciones y esferas sociales, siendo casi imperceptible.

Limitar las violencias de género a la esfera privada ha sido la apuesta de la modernidad, cuya instauración del patriarcado con su mandato de masculinidad ha facilitado llevar las violencias de género a lo doméstico, que, en palabras de Segato (2003), permite que el fenómeno sea normalizado, de fácil manejo, en tanto es dirigible y puede ser estandarizado desde un orden normativo (p. 132). Caer en el estudio de las violencias de género ubicadas exclusivamente en el plano de lo íntimo, o si se quiere, en el plano de las relaciones de pareja, es continuar limitando las violencias de género a lo privado de lo doméstico, desconociendo que fuera de este ámbito existen otras maneras, 
incluso más violentas, de ejercer control y poder sobre el cuerpo de las mujeres como territorio de posesión.

La violencia hacia las mujeres víctimas de maltrato y daños en relaciones de pareja, y que se atreven a denunciar a su agresor, es un fenómeno psicosocial complejo que se halla enmascarado en el entramado relacional en el que estas mujeres establecen intercambios no solo con sus agresores, sino también con el Estado, por lo tanto se constituye en un problema social, político y de salud pública, que responde a múltiples causas (Botero, 2020). Estas no han sido objeto de intervención en Colombia y prorrogan las violencias en los entornos íntimos e interpersonales, en donde comienza a evidenciarse una de las formas más letales de maltrato hacia la mujer (Segato, 2012). Si bien el registro y las intervenciones del Estado colombiano acerca de la violencia de género han venido avanzando históricamente, este adelanto ha sido muy lento, hasta el punto que aún hoy no existe una categoría o una norma que ampare las violencias de género dentro de las relaciones de pareja. Esta clase de violencia aún se encuentra huérfana; siendo una violencia invisible en las políticas que en materia de crimen existen en Colombia, quedando por fuera de todo el proceso de atención y justicia, por lo tanto ajena a la prevención y a la utilización de mecanismos que la erradiquen (Saldarriaga, Ariza, Cano y Saldarriaga, 2020.)

A pesar que desde el año 1996 esta problemática ha sido incluida y regulada en la legislación que atiende la violencia intrafamiliar, definida como cualquier tipo de "daño físico o psíquico, amenaza, agravio, ofensa o cualquier otra forma de agresión por parte de otro miembro del grupo familiar" (Ley 294 de 1992, p.2), la vulneración de sus derechos y las violencias contra ellas sigue siendo uno de los mayores problemas de la sociedad colombiana (Abella, Ahumada, Oviedo, Ramos \& Torres, 2017). La violencia contra la mujer puede manifestarse en forma de daño físico, sexual, psicológico, laboral, pérdida de su libertad, deterioro de su patrimonio económico que afecta su vida, su salud y bienestar psicológico, su integridad, así como a sus oportunidades y calidad de vida. Teniendo en cuenta que toda violencia contra la mujer, tanto en lo público como en lo privado, está enmarcada en relaciones de poder, esta se constituye en violencia basada en género (Naciones Unidas, 1993).

Por otro lado, es importante resaltar que en Colombia, al ser considerada la familia como núcleo básico de la sociedad y a su vez un derecho fundamental, amparado en la Constitución Política de 1991, en su Artículo 42, los funcionarios del sistema de justicia al atender las denuncias por violencia intrafamiliar, operan bajo la lógica de la protección jurisprudencial de la familia como institución básica de la sociedad y no sobre la protección de los derechos de las mujeres víctimas. Este asunto devela que el progreso legislativo y social no ha tenido el impacto esperado para el desmonte de las estructuras patriarcales dentro del Estado, reafirmando la reproducción de las prácticas de derecho tradicional, iusnaturalista y familista, lo que continua disciplinando la relación víctimaagresor de manera lineal y fragmentada, desconociendo las estructuras asimétricas jerárquicas) que fundan las violencias de género. 
En ese sentido, la atención de las violencias de género, mediante el delito por violencia intrafamiliar, fragmenta el accionar jurídico y sancionatorio en dos líneas: la administrativa y la penal, de las cuales, la primera es atendida en las comisarías de familia; que, según los lineamientos técnicos del Ministerio de Justicia y del Derecho (2012), son las encargadas de prevenir y atender este delito, haciendo la recepción de la denuncia, ofreciendo medidas de protección y restituyendo los derechos de las mujeres violentadas, mediante la concurrencia institucional, además de impartir justicia administrativa. En ese sentido, cualquier omisión o práctica re-victimizante por parte del aparato jurídico y denuncia reproduce la violencia hacia las mujeres. Esta acción se configura como violencia institucional de género, categoría acuñada por Bodelón (2014), para visibilizar un conjunto de prácticas y actitudes provenientes del patriarcado que han impedido la realización de un cambio en las estructuras institucionales, especialmente en el Estado y su aparato jurídico, y acotada jurídicamente en el año 2017 por la sentencia T 735 de la Corte Constitucional colombiana.

Aunque las comisarías de familia cuentan con los lineamientos técnicos para la atención de la violencia intrafamiliar a mujeres víctimas sobrevivientes de violencias basadas en género (Ministerio de Justicia y del Derecho, 2012), este trámite administrativo no logra superar las barreras en el acceso a la justicia por parte de las mujeres, ni garantizar el derecho a una vida libre de violencias. No obstante, existen serias limitaciones de esta acción administrativa de justicia, que se convierten en formas de revictimización ejercidas por la única instancia operativa para la atención de la violencia intrafamiliar, toda vez que esta presenta obstáculos no solo en la estructura del procedimiento, sino también en los escenarios físicos, la exigencia de material probatorio y la ineficacia de las sanciones administrativas, que se configuran, junto con las malas prácticas jurídicas, en una segunda agresión, esta vez perpetrada por el Estado y que deja múltiples consecuencias negativas en las mujeres víctimas a la hora de acceder al aparato de justicia.

En este sentido, esta investigación indagó por las experiencias de las mujeres víctimas denunciantes de violencia intrafamiliar, en el proceso de trámite de la denuncia. Esta indagación se orientó a develar las formas de violencia que también padecen las mujeres víctimas de maltrato en relaciones de pareja, cuando acuden al sistema jurídico para la protección y garantía de sus derechos. Los resultados de este estudio permiten revalorizar las voces de sujetos desconocidos, como vía dialógica para la construcción de saberes sociales situados y particularmente aportar al develamiento de un campo de estudios sobre violencias institucionales, a partir de las narrativas de las mujeres víctimas que se atreven a la denuncia.

\section{Método}

La investigación se realizó desde un enfoque cualitativo, con diseño fenomenológico-hermenéutico, utilizando el método narrativo, cuyo referente fundamental 
lo constituye la matriz mundo de la vida, mundo vivido del o los sujetos que lo viven y experimentan. El modo en que el mundo es vivido y percibido por una persona, como una realidad subjetiva, única y propia, exige ser estudiado mediante métodos fenomenológicos (Martínez Miguélez, 2004). La vivencia, lo vivido, eso que me pasa, es el elemento primordial de la narrativa. Siguiendo a Gadamer (1984), en la vivencia hay algo más que una experiencia puntual o momentánea. Lo que se manifiesta, aparece en la vivencia es la vida, el acontecimiento de la intensidad de la vida misma. De la vivencia nacen las expresiones, los sentimientos, los sentidos, los significados, los cuales pueden objetivarse mediante el relato de lo vivido. Este último expresa un conocimiento y una verdad, que no puede ser verificada por la metodología científica tradicional. La denuncia es el modo alternativo de narrar un acontecimiento, una escena en la que quien lo narra estuvo implicado, la vivió. Si bien, según Achugar (1992), el relato denunciante tiene dos funciones: ejemplarizante 0 de delación y la de ser patrimonio letrado de los acontecimientos, vidas y circunstancias de la historia, en ocasiones ignorada por la tradición hegemónica. En este estudio se optó por el uso de la narrativa en su papel de denuncia, por su valor de atención al otro y a las otras narraciones de los abusos de poder, de la acusación, la marginación, la delación del silencio oficial (Achugar, 1992). En este sentido, esta investigación expone como elemento central el registro de la voz de las víctimas denunciantes, sobrevivientes violentadas por sus cónyuges o exparejas, revictimizadas por el sistema penal de denuncia colombiano, toda vez que han tenido el coraje de denunciar a sus victimarios. Cabe precisar además que al reconstruir la memoria de lo vivido por las mujeres denunciantes de violencia intrafamiliar que participaron en este estudio, las investigadoras también se convierten en otro denunciante de lo vivido por las mujeres victimizadas, relatando públicamente la verdad de la vivencia de menosprecio, sometimiento y maltrato que de modo silenciosa padecen muchas mujeres en el contexto de la privacidad de la vida doméstica. Esta investigación, no tiene otra pretensión que sacar a la esfera pública las violencias contra las mujeres que ocurren en la esfera privada, a partir de la consideración de que el conocimiento científico-social debe tener un compromiso ético y político, especialmente con todas las formas de violencias que les impiden a las mujeres vivir en libertad y dignidad.

\section{Procedimiento y análisis de las narrativas}

Se recogieron las voces de las mujeres denunciantes, víctimas de violencia intrafamiliar, mediante entrevistas en profundidad que permitieron conocer, a través de sus narraciones, las vivencias y los significados que le otorgan estas sobrevivientes a todo el proceso e implicaciones del trámite jurídico ante el sistema judicial de denuncia de maltrato en sus relaciones de pareja. Además, se utilizó la observación participante en comisarías de familia, estrategia que posibilitó la aproximación contextualizada al fenómeno en cuestión, conocer el sistema de denuncia y su tratamiento jurídico 'desde dentro' y sin lo cual no hubiese sido posible identificar y develar las formas enmascaradas de violencias de género hacia las mujeres denunciantes, no sólo en el sistema mismo, 
sino en los funcionarios que reciben y tramitan las denuncias. Igualmente, a través de la observación participante in situ se pudieron presenciar las delaciones, comportamientos y discursos que dan cuenta de las barreras que existen en el sistema jurídico de denuncia, para valorar las denuncias y experiencias de las mujeres violentadas: actos de omisión, sexismo (Fenton, 1998), micromachismos(Bonino, 2004), son expresiones de la imposición de normas androcéntricas que privilegian la superioridad de los varones masculinos, heterosexuales y enfatizan la inferioridad femenina. La discriminación hacia las mujeres que acuden a las comisarías de familia, fiscalía, juzgados, es manifiesta en actitudes de devaluación o desprecio de los funcionarios por los reclamos de justicia y protección de sus derechos, por considerar que sus denuncias no se inscriben en los roles tradicionalmente asignados a las mujeres. Así mismo, durante la recepción de la denuncia, los operadores de justicia, mediante manipulaciones coercitivas cuestionan la validez del relato de la mujer violentada interpelando su responsabilidad en la provocación del agresor, objetando su capacidad para vivir en autonomía, tretas de intimidación sutil por posibles consecuencias legales por su denuncia, actitudes de micropoder frente a las mujeres que se configuran como formas de violencia institucional y re-victimización. Según Bonino (2004), estos comportamientos sexistas y micromachistas son dispositivos mentales incorporados y automatizados en el proceso de socialización de género, como hábitos de funcionamiento para mantener los estereotipos de género y ejercer gobierno sobre las mujeres.

Las narrativas fueron aportadas por tres mujeres víctimas de violencias de género en sus relaciones de pareja que denunciaron ante el aparato jurídico de sus localidades. Es preciso destacar que el acceso a las víctimas no es fácil, debido a las emociones de vergüenza, desconfianza y dolor psicológico que supone esta experiencia. En razón de ello, solo se pudo contar con la aceptación de tres denunciantes, a través del consentimiento informado. Para la validez y confiabilidad de los resultados, se utilizó la triangulación de actores sociales: una abogada del Colectivo Litigio Estratégico Corporación Colectiva Justicia Mujer de Medellín -Antioquia, Colombia y los testimonios de funcionarios de comisarías de familia: una trabajadora social, una psicóloga y tres jueces. Todos ellos familiarizados e implicados profesionalmente en el sistema jurídico de recepción de denuncias de violencias de género y su trámite jurídico-administrativo.

Las narrativas testimoniales se generaron, a partir del análisis de los relatos de las mujeres denunciantes, a partir de los cuatro niveles analíticos propuestas por Sparkes y Devís (2008): análisis de paradigmático de contenido, análisis holístico del contenido, análisis categórico de la estructura y análisis holístico de la estructura. En el primer nivel, en el análisis paradigmático de los contenidos de las narrativas, se examinaron las similitudes y diferencias en los relatos de las experiencias vividas por las mujeres denunciantes, extrayendo con ello los temas centrales que constituían sus narrativas. Esto se logró dividiendo los relatos en pequeñas unidades de contenido, sometiéndolo a un procedimiento descriptivo, lo que condujo al siguiente nivel de análisis holístico de contenido, en el que cada sección del relato se analizó en relación con todo el conjunto de 
la experiencia narrada. Posteriormente se examinaron las percepciones y valores de las mujeres, involucrados en sus relatos, buscando similitudes y diferencias en cómo estas mujeres contaban sus propias experiencias de violencia intrafamiliar, lo que configuró el tercer nivel de análisis categórico de la estructura del testimonio. Finalmente, en el nivel de análisis holístico de la estructura testimonial se estudiaron las formas en que evolucionaron sus vidas, a partir del acontecimiento de la violencia que padecieron en sus relaciones de pareja y luego de la experiencia de la denuncia ante el sistema jurídico colombiano, en sus distintos lugares de vida.

Para el procesamiento de la información, se utilizó el software Atlas ti y el análisis narrativo se realizó utilizando la estrategia analítica estructurada y de comparación constante de la teoría fundamentada (Glaser \& Strauss, 1967; Glaser, 1992; Strauss \& Corbin, 2002). El proceso de codificación, categorización y contrastación, permitió la emergencia de interpretaciones en dos niveles: descriptivo e interpretativo-comprensivo. En estos dos niveles, los análisis siguieron una senda tipo bucle que permitía flexiblemente ir desde dentro hacia afuera y de lo singular o micro, hasta lo general o macro de las experiencias. Todo esto develar las facetas más particulares del fenómeno (Martínez, 2004). Finalmente, el procedimiento analítico e interpretativos de las narrativas, permitió su condensación en cuatro categorías, descritas en el siguiente gráfico: 
Revista Punto Género N. 16 Diciembre de 2021

ISSN 2735-7473 / 169- 193

\section{Gráfico1. Categorías emergentes}

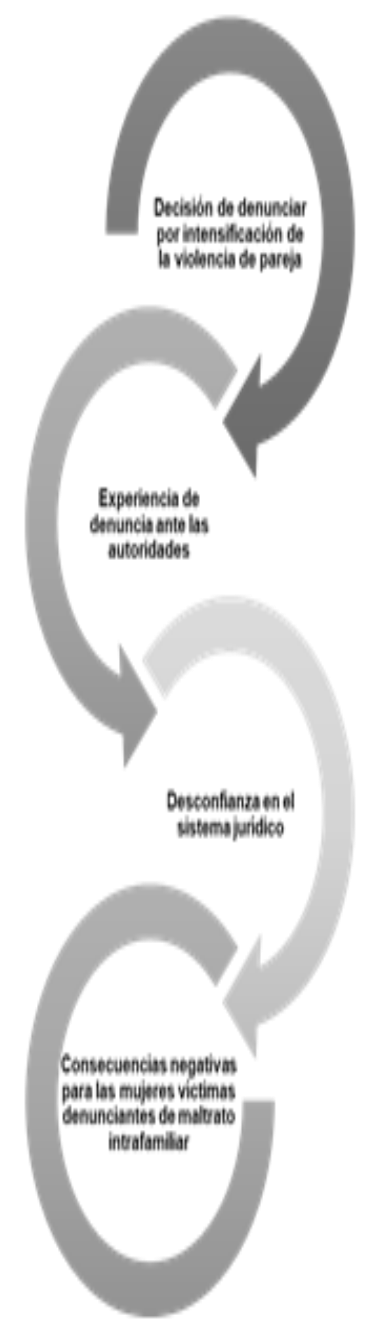

Fuente: elaboración propia.

Para la comprensión de las narrativas y el resguardo del anonimato, se usaron las convenciones indicadas en la siguiente tabla: 
Tabla No. 1. Convenciones

\begin{tabular}{cc}
\hline Convenciones & \multicolumn{2}{c}{ cación } \\
\hline Mujer 1 & $\mathrm{M} 1$ \\
\hline Mujer 2 & $\mathrm{M} 2$ \\
\hline Mujer 3 & $\mathrm{M} 3$ \\
\hline Abogada Litigio Estratégico & $\mathrm{ALE}$ \\
\hline $\begin{array}{c}\text { Observación 1 audiencia por } \\
\text { violencia intrafamiliar en flagrancia }\end{array}$ & $\mathrm{O}$ \\
\hline $\begin{array}{c}\text { Observación 4 recepción de la } \\
\text { denuncia por violencia intrafamiliar }\end{array}$ & $\mathrm{VIF}$ \\
\hline
\end{tabular}

Fuente: elaboración propia.

\section{Resultados}

\section{Decisión de denunciar por intensificación de la violencia}

La decisión de las mujeres víctimas de violencia de género en sus relaciones de pareja, de denunciar a sus agresores, usualmente acontece luego de atravesar un proceso de conciencia, toda vez que, "La violencia doméstica responde a un patrón de comportamiento continuado en el tiempo con elementos de comportamientos abusivos" (Hester, 2014, p. 238), que terminan por detonar la necesidad de buscar ayuda en el sistema jurídico. Es importante señalar, que todos los procesos son diferentes y esto atiende tal como lo promulga la Ley 1257 de 2008, a que las mujeres pueden atravesar por múltiples violencias, ya sean físicas, psicológicas, económicas, sexuales y patrimoniales, que si bien, tienen un impacto diferente sobre cada persona, es la continuidad y la intensificación de las mismas, uno de los factores que precipitan la denuncia. "La decisión de denunciar se toma tras un tiempo largo de acumulación de violencia, cada vez más intensa y/o frecuente que puede llegar hasta el homicidio (sic) y sus derivadas, causando gran deterioro físico y mental” (Bodelón, 2014, p. 51). Lo anterior, representa una situación que es alarmante, ya que como lo reporta el último informe sobre el estudio global de homicidios de la Organización de las Naciones Unidas -ONU- (2019): seis de cada 10 mujeres son asesinadas por su pareja, expareja o algún miembro íntimo de su familia. Fenómeno que se visibiliza en este estudio, tal como aparece en la siguiente narrativa:

"Le dije yo que ya no aguantaba más, que lo iba a dejar y él se pone muy agresivo, él dice que me mata si me voy, me trata muy mal, me dice palabras 
como malparida, que esta buena para cogerla y picarla, que si yo lo dejo no me va dejar en paz, que me hace la vida imposible, me dijo que me largara de esa casa y que no podía sacar nada, solo la ropa, me quitó la cédula, la tarjeta de identidad de la niña, los pasaportes, y me dio unos puños y unas patadas, cuando llegó la policía empecé a empacar la ropa y me fui, él seguía llamándome a amenazarme que no podía verme con nadie porque me mataba, esa violencia nunca ha parado desde que me fui de la casa" (O3AVIF, agosto 1 de 2020).

Cabe señalar que, en la misma dirección, no sólo está la acumulación o el incremento de la violencia física, sino que las agresiones también están justificadas en las estructuras culturales del patriarcado sobre la dominación y posesión de los cuerpos de las mujeres (Segato, 2018). Estas expresiones de posesión, se evidencian en comportamientos de pertenencia que ejercen los hombres hacia las mujeres, justificando las agresiones, motivadas por celos de parejas o exparejas que además de ejercer la propiedad sobre el cuerpo, también lo hacen sobre los comportamientos, disfrazando las expresiones del amor romántico, las lealtades a las uniones afectivas y reforzando la cultura patriarcal que ha autorizado a los hombres a ejercer control sobre la vida de las mujeres (Peña, 2018). En consonancia con esto, una de las mujeres narró cómo su expareja la victimizaba con controles cotidianos:

"Mi expareja es excesivamente celoso, yo me fui a realizar una vuelta al seguro en Rionegro y entré a un almacén, y a él lo llamaron y le dijeron que yo estaba con un señor que me estaba comprando cosas y me trato terrible, me dijo que me esperaba al llegar al municipio ahí en el trasporte para que le diera explicación de las cosas, y así fue, yo me estaba bajando del taxi y él estaba esperándome y me obligó a ir a la casa de él y eso que yo ya no tenía nada con él, la relación solo es por el hijo que hay en común. Yo traté de explicarle y eso le daba más rabia y empezó a golpearme y cuando la mamá vio que estaba dando duro, se metió y me lo quita de encima, él no me dejaba salir de la casa, y mientras la mamá trataba de calmarlo el más se enojaba y le daba golpes a la pared y me decía que le diera mi celular para revisar con quien era que yo hablaba y yo le dije que no, porque sabía que me lo dañaba y esa es mi herramienta de trabajo, sacó una navaja y la mamá lo logro agarrar antes de que me chuzara, el soltó la navaja y yo salí corriendo, en ese momento llegó la policía, un policía escuchó cuando me dio una cachetada y lo capturó y se lo trajo a la estación" (O1AVIF, julio 30 de 2020).

Así mismo, dentro de este contexto, la negativa de los hombres frente a la ruptura de las relaciones afectivas, confluye con otros fenómenos problemáticos como el consumo de sustancias lícitas o ilícitas por parte de los agresores, convirtiéndose en otro factor que precipita la denuncia por parte de las mujeres, ya sea como estrategia para buscar el cese de las violencias o con el fin de salvaguardar su vida y su integridad emocional, tal como lo exponen Herrera Paredes y Ventura (2010), el alcoholismo registra gran porcentaje de situaciones en las que las mujeres son agredidas por sus 
compañeros conyugales, trayendo consecuencias físicas o psicológicas, estas últimas afectando su autoestima y predisponiéndolas a otras alteraciones y padecimientos emocionales. Así lo narró una de las denunciantes:

"Yo me separé de mí expareja porque era un borracho, él me acosa y me persigue hasta en mi casa cuando se emborracha, porque no quiero regresar con él, me hace escándalos en toda parte, me dice perra vagabunda. Yo tuve una relación de 7 años con él, de donde hay una niña, sin embargo, me cansé de los tratos violentos y de que le pegara cada vez que le daban celos o estaba borracho. Es más, me ha hecho renunciar de mis trabajos, porque llega a ponerle problema a los clientes, además cuando me ve en la calle me agarra a la fuerza y me retiene para que lo escuche y le preste atención, a mí ya me da miedo salir sola, yo lo veo y arrancó a correr porque me da miedo que él me haga algo, con él no se puede porque el consume mucho alcohol, él nunca va a cambiar" (O4RDVIF, agosto 15 de 2020).

Por otra parte, el peso de las construcciones sociales y culturales adquieren un lugar de coacción y cumplen un lugar moralizador hacia las mujeres, que van desde la normalización de los actos violentos, hasta los ideales culturales sobre la familia, imponiendo a las mujeres la protección, cuidado de sus hijos y el mantenimiento del hogar, causando vergüenza y culpa frente las rupturas afectivas (Segato, 2003). Esta situación que se encuentra legalizada y amparada en la Constitución Política Colombiana, en su Artículo 42, que define a la institución familiar como “ (...) el núcleo fundamental de la sociedad” (Constitución Política de Colombia, 1991, Art. 42), constituye una fuerza de presión social y estigmatiza a las mujeres que interponen denuncias por violencia contra ellas. La metáfora de la familia como esencia de una sociedad ideal, se fundamenta en la naturalización de las relaciones de género en un orden patriarcal que responsabiliza a las mujeres del cuidado del hogar, las encierra en el mundo de lo doméstico y las destina hacia el compromiso del matrimonio y a la maternidad. Estos modos de concepción de los géneros, develan los órdenes simbólicos en los que las sociedades occidentalizadas han impuesto el género como una categoría que escinde la vida cotidiana en roles jerarquizados de hombres y mujeres. Estas representaciones soportan las configuraciones familiares y estas a su vez reproducen las costumbres culturales y mantienen estos órdenes sociales (Díaz-Alzate, Durán-Palacio \& Gómez-Durán, 2021). La legislación colombiana, se haya fuertemente influenciada por la teoría del sistema familiar de Parsons (1978) quien concibió la familia como una institución nuclear, caracterizada por la afectividad, la privacidad, la transmisión y la asunción de roles ocupacionales fijos. El padre-esposo, desarrolla el rol instrumental de proveedor que lo obliga a estar fuera del hogar, mientras la madre-esposa debe encargarse del hogar, realizando tareas domésticas y de crianza (p.51). En palabras de Puyana Villamizar (2019), el término núcleo básico de la sociedad, esconde rasgos de la cultura patriarcal que funda la familia en las relaciones de poder del padre y esposo sobre la mujer, sus hijas e hijos, quienes deben obedecerlo (p.52) 
La experiencia de esta imposición social se ilustra en este relato:

"Yo realmente la pensé mucho para denunciar, el me pegaba, me encerraba desde el embarazo del niño y yo todo eso lo tapaba para que mi familia no se diera cuenta, cuando yo me fui de la casa era con la ilusión de construir una familia, porque yo fui mamá muy joven y pues uno con dos hijos de dos papás diferentes ya la gente que iba a decir, a mí me daba pena volverme a la casa de mis papás y tampoco tenía dinero para irme a vivir sola, con los niños, realmente yo esa decisión la tomé porque mi familia se dio cuenta de la violencia, y mi mamá habló con mi papá y solo me recibían si les prometía que no volvería con mi ex" (M1, Junio 15 de 2020).

Tal como se ha expuesto, los factores precipitantes para la denuncia en las relaciones de pareja, también llamada en el sistema jurídico colombiano como violencia intrafamiliar, se ven reflejados en el incremento de las violencias, las cuales se refuerzan en los comportamientos tradicionales patriarcales de dominación hacia las mujeres, siendo la denuncia la única herramienta formal para la protección de los derechos de las mujeres. Sin embargo, el inicio del procedimiento jurídico no suscita en ellas sensación de cuidado o protección legal. En muchas ocasiones, luego de la denuncia sus exparejas incrementan las agresiones y amenazas. El estudio de Goodman, Bennett \& Dutton (1999), evidenció que mientras el proceso judicial está en marcha las mujeres víctimas de violencia son más vulnerables, ya que el agresor no es encarcelado mientras espera el juicio y puede regresar a casa, a pesar de las objeciones de la víctima. Al mismo tiempo que el caso se abre paso en el sistema penal, el maltratador puede agredir a la víctima, a sus hijos o a otros miembros de la familia, destruir su propiedad en represalia por haberlo denunciado ante las autoridades de justicia o como una forma de intimidación para obligarla a regresar a la relación conyugal. Por lo tanto, la fase de denuncia debe considerarse como un momento de extrema vulnerabilidad de las víctimas.

\section{Experiencia del contacto con las autoridades}

Posterior a la denuncia, la experiencia del contacto de las mujeres víctimas de violencia intrafamiliar con las autoridades, es el inicio del proceso de atención integral para las víctimas, sin embargo, no siempre se convierte en un proceso eficiente y operativo para la garantía de los derechos de las mujeres, toda vez, que como lo estableció la Sentencia T-735 de la Corte Constitucional de Colombia, los operadores de justicia colombianos, ejercen violencia institucional, ya sea por acciones $u$ omisiones que pueden causar re-victimización en las personas que utilicen el sistema (Corte Constitucional de Colombia, 2017). En ese sentido, el acceso a la justicia para las mujeres se convierte en un proceso hostil, donde no solo se enfrentan al victimario, sino también con estereotipos de género que, atravesados por una cultura patriarcal, permean los funcionarios y profesionales quienes no alcanzan a dilucidar la re-victimización que 
ejercen, haciendo que la experiencia de las mujeres por el paso del operador de justicia sea traumática:

"Yo no tuve una buena atención en ninguna parte, ni en un centro de conciliación privado, ni en una comisaría y menos en un juzgado, es que ni siquiera los espacios físicos, en ninguna parte del sistema jurídico, tampoco en los abogados, fui yo la que redacté mi caso y si eso iba a ser así no creo que necesitara pagarle a un abogado un monto exagerado de dinero, para que me dijeran que la violencia intrafamiliar es muy difícil de probar, esa es la respuesta del sistema jurídico para una mujer como yo, que por tener empleo y formación pasé de ser la víctima, a disputar la custodia de mis hijos, a tener más responsabilidades económicas que mi expareja, debido a mi poder adquisitivo" (M3, Mayo 15 de 2020).

En ese sentido, las mujeres siguen siendo una población inadecuadamente atendida, vulnerabilizada y polivictimizada (Finkenlhor, Ormrod \& Turner, 2007), a quienes la violencia basada en género, no solo constituye una manifestación de dominación de lo masculino sobre lo femenino en las relaciones de pareja, sino que adquiere múltiples formas de desvalorización que enmascaran en la cotidianidad a la cultura patriarcal, que también ha contribuido a imponer en la concepción tradicional del discurso jurídico y la jurisprudencia colombiana, la idea de la mujer como garante de la estabilidad de la institución familiar. De acuerdo con Puyana Villamizar (2019), si la familia es la responsable de la educación moral de la prole y del buen comportamiento de los sujetos en la sociedad, y como base de este funcionamiento se circunscribe en el papel cumplido de la madre, entonces es en ella en donde recae la culpa del desequilibrio psíquico de los hijos y de los problemas sociales que estos puedan generar. Para Palacios Valencia (2008), estas exigencias hacia la mujer madre, operan como dispositivos de configuración de su actuación en la familia y la sociedad. Desde un ordenamiento tradicional de la familia, el reconocimiento de la diferencia de las mujeres, opera como justificación y legitimación de la desigualdad respecto al hombre, padre, adulto, proveedor y figura de autoridad. De igual modo, la familia patriarcal se presenta como el escenario de polarizaciones binarias jerarquizadas y excluyentes: masculino - femenino, marcando los límites entre lo natural y lo normal frente a lo transgresor y disfuncional. Asunto que dispone no solo de los mecanismos educativos, sociales, jurídicos de control y regularización, en la definición de las identidades y los roles de los hombres y las mujeres, sino que, además se mantiene y perpetúan en las actitudes y actuaciones de hombres y mujeres, funcionarios de la administración de justicia, quienes se mantienen en la hegemonía de la superioridad del ser del varón y del padre frente a las mujeres. En este posicionamiento, justifican las actuaciones del agresor denunciado, desestiman la continuidad del trámite de denuncia de la víctima, le proponen la vía de la conciliación con su victimario o la culpabilizan de las consecuencias económicas y emocionales para sus hijos, resultantes de la querella jurídica. 
Si bien, los lineamientos técnicos para la atención en violencia intrafamiliar dentro de las comisarías, ordenan que la mujer víctima denunciante sea atendida en un entorno de confidencialidad, donde se pueda preservar la identidad y que además su atención debe ser integral (Ministerio de Justicia y del Derecho de Colombia, 2012), en la mayoría de los escenarios de escucha y recepción de las denuncias, las condiciones de los espacios físicos para evitar la exposición y vulneración de la mujeres es inexistente y se configuran como una nueva forma de re-victimización, ya que algunas de las comisarías de familia no disponen de una locación para la adecuada atención de las víctimas, lo que impide garantizar que el acompañamiento sea acorde a las necesidades reales de la situación y no genere efectos contraproducentes en las mujeres. En el siguiente relato se aprecia la descripción de la situación vivida por una de las mujeres denunciantes:

"Una de las experiencias más traumáticas y desagradables para mí fue la asistencia en la comisaria, donde me tocaba sentarme a confrontarme con mi expareja que seguía violentándome en razón de que la psicóloga consideraba que lo que estaba mal era la comunicación, me tocó recibir esas asesorías en el archivo de la comisaria, donde únicamente había una mesa y un montón de cajas de cartón donde guardaban las cosas y los informes, literalmente uno le tocaba quedarse parado hasta que traían las sillas que iban cogiendo de otros escritorios" (M3, mayo 15 de 2020).

De tal manera que el trámite de denuncia por violencia intrafamiliar en Colombia, además de implicar una exigencia de la víctima de exponerse frente a un sistema jurídico hostil, y permeado por la cultura patriarcal, también tiene una deficiencia en los procedimientos, espacios físicos de atención para las víctimas, y los protocolos, infringiendo no sólo los lineamientos técnicos, sino configurándose como otra forma de violencia y de vulneración de los derechos de las mujeres víctimas sobrevivientes de violencias de género.

Por lo tanto, en la misma dirección de las omisiones o negligencia, también aparecen la apropiación de los estereotipos de género, entendidos como ideas socialmente establecidas sobre los roles femeninos y masculinos, que se asignan a través del proceso de socialización y adopción de la cultura (Ashmore \& Boca 1979), que permean a los funcionarios encargados de la atención, convirtiéndose en una expresión de malas prácticas jurídicas dentro del acceso a la justicia, generando sesgos que mantienen, promueven el rol doméstico y el enfoque 'familista' que se le ha adjudicado a las mujeres históricamente. El procedimiento policial se describe en esta narrativa:

"En un momento un policía llegó y me preguntó que, si yo era una mujer casada, que siendo casada no me diera pena terminar un matrimonio, y mucho más sabiendo que yo era casada por la iglesia, yo seguí recogiendo mis cosas y cuando las empecé a sacar para la moto, ellos se pusieron a conversar con mi ex suegra y mi expareja, tomando partido por lo que él estaba manifestando, le decía que él era un hombre muy trabajador, que mirara yo como le pagaba. Dado todo esto, yo sentí que los policías se fueron en contra mía, a mirarme como con 
desprecio, como la sucia que no vale nada. Para mí esto fue muy incómodo, yo sentía mucho miedo y ganas de salir corriendo de allí, pero mi expareja empezó a decirme que laja de mujer, que pena que se había metido conmigo, que debía darme pena y vergüenza de la gente y de la policía dañar la familia" (M2, abril 20 de 2020).

Esto nos conduce a exponer que el enfoque familista, también atraviesa a los funcionarios que acompañan el acceso a la justicia, convirtiéndose en una forma explícita de re-victimización para las mujeres, ya que dados los arraigos culturales el mantenimiento de la familia recae sobre la mujer.

Cabe señalar, que la percepción de incomprensión que tienen las mujeres denunciantes, por parte de las autoridades y funcionarios hacia ellas, incluye las acciones jurídicas dentro del procedimiento administrativo, hasta la forma de operación y los entornos para la atención, trayendo como consecuencia una grave desconfianza en el inicio y desarrollo del proceso, tras una inadecuada orientación y asesoramiento (Bodelón, 2014). Los funcionarios encargados de la recepción de la denuncia, dan información confusa sobre el procedimiento, el proceso jurídico en sí mismo supone demasiados trámites que demandan tiempo y dinero para las víctimas, además de las amenazas constantes del agresor, que no son atendidas efectivamente.

\section{Desconfianza en el sistema jurídico para la protección de los derechos de la mujer}

Dadas las múltiples dificultades que tiene las mujeres para el acceso a la justicia en las cuales son re-victimizadas en el trámite del delito de violencia intrafamiliar, este proceso causa en ellas desconfianza hacia el sistema y el Estado, evidenciado en la poca efectividad para garantizarles protección y restablecer sus derechos. Tal como se ha venido exponiendo, se ven develadas las limitaciones operativas de las comisarías de familia en la atención y locación; y a ello se le suma la percepción de las víctimas de la incapacidad de garantizar el cumplimiento de las medidas de protección, convirtiéndose en una de las causas más significativas de miedo y desconfianzas de las mujeres frente a la capacidad operativa y de respuesta del sistema, ya que temen a la reacción del agresor, tras la denuncia, y a la presencia de una mayor violencia o a la pérdida de su vida luego de recurrir al sistema (Bodelón, 2014). En este relato se corrobora lo anteriormente expuesto:

"Yo esperaba que realmente hicieran algo, que lo capturaran, porque he conocido casos de personas que les ha pasado lo mismo que a mí y ahora están en la cárcel, pero con respecto a mí, pareciera que la justicia no sirve porque con él nunca hicieron nada, él me perseguía cuando me veía en la calle, se iba detrás de mí, iba a mi casa, pero esa medida de protección no servía para nada, muchas veces llamé a la policía y no llegaba y cuando si iba me decía la policía que si lo metían a la cárcel era solo con el fin de meterle un susto, él lo incumplió muchas veces la medida de protección y tampoco pagó las multas, y es que ni por 
asustarlo lo metieron ni unos días, ni un rato, con lo que pasó conmigo no creo que eso sirva, si hubiesen hecho algo yo podría decir que si sirve y que deberían seguir con el proceso, pero a mí todo lo que me dijeron que iban a hacer nunca se hizo nada, yo seguí teniendo el mismo miedo de que me hiciera algo y desmotivada porque sabía que poner la denuncia no garantizó que él me dejara tranquila" (M1, junio 15 de 2020).

Por otra parte, se logra develar una percepción negativa de las mujeres sobre el sistema de justicia, toda vez que en sus experiencias les han causado un impacto desfavorable, donde se ha desestimado la credibilidad de sus testimonios, ya que como se ha evidenciado anteriormente los funcionarios están atravesados por el sistema patriarcal, manteniendo la presunción de inocencia de los acusados, y adicionalmente con la débil capacidad probatoria que tiene el sistema, se continua re-victimizando las mujeres en todo el proceso (Naredo, Casas y Bodelón, 2014). En ese mismo sentido, la siguiente narrativa lo evidencia:

"El sistema probatoria colombiano es muy difícil de entenderlo de manera amplia porque mantiene la creencia que aunque no está regulado de esa manera, exige que todo lo que uno diga debe ser probado y eso incluye las víctimas de la violencia, y además cree que la forma de probarlo es por un medio audio visual diciéndole a las víctimas usted tiene un video, un audio, tiene fotos, o cómo va a probar eso, es así como desvirtúan o desestiman que el testimonio como tal es en sí mismo un elemento probatorio, entonces ahí aparece el prejuicio, porque a las mujeres no se les cree el relato de la misma manera que a los hombres, la mujer llega y dice me amenazó de muerte y el agresor dice yo no le dije eso, ella entendió eso, yo estaba desesperado o tenía mucha rabia, y empiezan a disminuir la responsabilidad de él y a creer que hay una razón para que el haya dicho lo que dijo y empiezan a desvirtuar la veracidad de lo que ella está narrando" (ALE, Septiembre 1 de 2020).

Así mismo, la falta de formación de algunos profesionales en el enfoque de género, como una categoría que permite comprender las diferencias e inequidades que existen entre hombres y mujeres (Serrano, 2012), se intensifican las formas en las que aparece la violencia institucional, dado que los profesionales no alcanzan a comprender y dimensionar la configuración de las violencias de género al interior de la familia. Para superar estas limitaciones, es necesaria una adecuada formación, donde se logren vencer las resistencias que se tienen con los enfoques de género, conceptos y metodologías feministas, y que además se desarrolle una sensibilidad y real empatía con las víctimas de violencia de género (Bodelón, 2014). Sin embargo, pese a que Colombia recientemente visibilizó la violencia institucional en la Sentencia T 735, y por medio de sentencias de la Corte Constitucional, como la T 338 de 2017, donde declara la inclusión obligatoria de la perspectiva de género en la administración de justicia y ordena a todos los jueces de la Nación tomar capacitación sobre el enfoque de género y su aplicación en la administración de justicia, persisten actitudes renuentes de algunos profesionales sobre 
la necesidad de formación especializada en género, ya que dan por entendido que la normatividad en sí misma es suficiente para la ejecución de sus labores. Así lo testimonia este relato:

"Este proceso ha sido algo muy largo y difícil, yo llevo tres años y realmente solo he encontrado apoyo en la secretaría de la mujer, porque es el único lugar que yo sentí que intentaron ayudar, porque la comisaría fue un fiasco, esa psicóloga de la comisaría, no tiene idea de lo que es la violencia emocional, lo único que ella hizo fue exponerme de nuevo ante mi agresor, por otro lado ese juez que no cree en los hechos de violencia contra la mujer, porque mi actual abogada tuvo una audiencia a la siguiente semana de la mía, en ese mismo juzgado con una mujer que además tuvo violencia física, donde su hijo adolescente fue a testificar, que el señor además abusaba sexualmente de un niño con discapacidad cognitiva y en una de esas salidas al pasillo mi abogada le dijo que él estaba re- victimizando a la mujer y él le contestó que era eso, que a las mujeres medio se les dice cualquier cosa y ya son víctimas y ya son abusadas, él decía reiteradamente que no había víctima de nada" (M3, mayo 15 de 2020).

Este conjunto de prácticas victimizantes, estereotipos de género y obstáculos para acceso a la justicia, han generado en las mujeres una desconfianza en el sistema jurídico para la protección de sus derechos, propiciando que las víctimas en muchos casos opten por el desistimiento o abandono de los procesos, así mismo, que se cuestione la formación ética de los profesionales y la capacidad de impartir justicia de manera objetiva e imparcial, situación que en lugar resarcir la condición de víctima de las mujeres, termina causando daños morales y consecuencias negativas a las que se deben enfrentar luego de terminado el proceso.

\section{Consecuencias negativas para las mujeres víctimas de violencia intrafamiliar}

Tal como se ha ido evidenciando en los resultados de la presente investigación, es posible dar cuenta que las mujeres que además de haber sido víctimas de múltiples violencias, las cuales van desde la cotidianidad, la normalización y/o minimización de comportamientos violentos; también, se enfrentan a consecuencias negativas, tanto psicológicas, como físicas y económicas, situación que en algunas ocasiones dificulta las rupturas de los ciclos de la violencia o que exista la reparación de los daños emocionales que causan los hechos de violencia. Para Vásquez (2007), "la violencia degrada la integridad de la mujer provoca inseguridad, disminución de la autoestima, incertidumbre, desesperanza y desvalorización; además coarta sus posibilidades de desarrollo personal y anula su autonomía originando la depresión” (p. 91).

De acuerdo con Vásquez (2007), el testimonio de la abogada de litigio estratégico expone las secuelas que dejan las experiencias de denuncia de las mujeres víctimas de maltrato en relaciones de pareja: 
"Hay consecuencias negativas desde el punto psicológico en la que existe la justicia para las mujeres, considero es que toda la justicia para una mujer víctima de violencia basada en género, debe estar acompañado de un equipo psicológico, así la agresión sea lo que parezca mínimo, porque nunca es mínima, a veces cuando la agresión es psicológica puede ser más devastadora que las agresiones físicas, la diferencia es que no está echando sangre pero está herida es visible en los daños, otro ejemplo la violencia patrimonial, la inasistencia alimentaria, así sea un hecho de violencia que no tiene ni sangre, ni fracturas, ni depresión, ni ansiedad, ni todo lo que se produce con las otras violencias, genera sensación de rabia e impotencia, porque la plata no está para el mantenimiento de los hijos, incluso en eso también se necesita acompañamiento psicológico porque lo que está de fondo es un hecho que si le produce a las mujeres efectos devastadores en la salud mental, por ejemplo, un defensor de familia en Apartadó me dijo, doctora la condiciones que tenemos para que la audiencia no quede mal, es que a todos los hombres les ponemos cien mil pesos, y mi pregunta fue ¿cómo es que una persona puede convertir una paternidad en cien mil pesos?" (ALE, septiembre 1 de 2020).

Así las cosas, es posible afirmar que los daños morales y emocionales de las mujeres víctimas de violencia intrafamiliar, pueden causar daños irreversibles en su comportamiento y en su salud mental, "Cuando la mujer es maltratada las secuelas pueden ser físicas o psíquicas; estas últimas tiene un carácter más duradero y provocan la perpetuación del sufrimiento, constituyendo una causa de discapacidad" (Vásquez, 2007, p. 92). Por tanto, las mujeres que han sido víctimas de violencia en sus relaciones de pareja están expuestas y son propensas a contraer trastornos depresivos y trastornos de estrés postraumático (Portal de Salud de Murcia, 2010). Las secuelas negativas invisible e invisibilizadas, se mantienen por mucho tiempo en la subjetividad de las mujeres victimizadas y requieren de acompañamientos psicosociales específicos. Así lo ilustra una de las sobrevivientes:

"Yo aún vivo con miedo porque él es capaz de tomar represalias sobre mí, él es capaz de volverme a agredir porque él es muy violento y no le importa desafiar nada. Yo aun después de intentar separarme de él, tengo mucho miedo, el me habla para que lo deje ver el niño y el de una me amenaza, me intimida y me manipula me dice que yo soy la culpable de que él este lejos del niño, es tanto que yo le digo que organicemos todo por la vía legal y él me dice que no, que el por allá no va, que yo siempre me tiro en todo. Yo con todo esto realmente me pongo que no sé qué hacer, hasta lloro, de verdad él me da mucho miedo, yo siento que no me voy a poder librar de mi expareja nunca" (M1, junio 15 de 2020).

Por otra parte, sumado a los daños en la salud mental y física de las mujeres, las prácticas negligentes y poco empáticas de las instituciones y los profesionales, para llevar los procesos administrativos, la imposición de sanciones y las medidas de protección, también causan efectos negativos en las mujeres, puesto que, además de padecer 
violencia intrafamiliar, también se convierten el víctimas de violencia institucional, lo que causa desesperanza producto de los malos tratos dentro del sistema; lo anterior, ubica a las mujeres en un constante estado de indefensión y re-victmización, con altos riesgos de ser sujetos de vulneración de derechos humanos y padecer grandes obstáculos para el acceso a la justicia. En otras palabras:

"Todo este proceso, se hizo en un momento en el que yo estaba muy vulnerable, estaba muy enferma y deprimida y la abogada que me acompañó en ese momento me dijo que demostrar violencia emocional y psicológica era casi imposible, entonces que la mejor opción era realizarlo ante conciliación. Yo volví a cambiar de abogada y ella también lo consideró así, me expuso que era lo mejor que podíamos lograr, entonces yo estaba muy vulnerable y venia de muchos meses de escuchar que yo no servía para nada, que era una pésima mamá y lamentablemente yo no tenía conocimiento de cómo se llevaba un proceso de estos entonces desde mi estado emocional devastado, yo aceptaba todo lo que me sugerían, con la esperanza de poder separarme de mi ex pareja, sin embargo él es una persona sumamente difícil, me tocó bloquearlo de WhatsApp, pero el encuentra la manera de fastidiarme sobre todo con mis hijos, todo el tiempo y les dice a ellos que yo no hacía nada bien y esto vuelve y me afecta muchísimo, me pone insegura como las primeras veces, a pesar de que han pasado casi tres años desde que inicie este calvario... Ilanto" (M3, Mayo 15 de 2020).

Finalmente, si bien las agresiones que reciben las mujeres se presentan de diversas formas, tanto el proceso del trámite administrativo, como las exposiciones a continuas formas de violencias por parte de sus parejas, causando daños psicológicos, morales y personales irreparables, que requieren de acompañamiento profesional y psicosocial constante, con el fin de reestablecer las dinámicas personales y sociales.

\section{Consideraciones finales}

La naturalización de las violencias de género y la influencia del patriarcado, han facilitado la perpetua orientación conservadora y la necesidad de confirmar el prestigio y el poder masculino, ante los hechos de violencia contra las mujeres. Esto ha logrado mantener la jerarquización social del género, las prácticas de dominación, subordinación, propiciando la re-victimización ante los delitos amparados por la legislación colombiana, al menos en el caso de la tipificada violencia intrafamiliar.

El enfoque reforzador de la familia en las instituciones estatales, la legislación y el derecho puesto en acción, perpetran en gran medida las violencias, ya que los nuevos fenómenos contemporáneos, dinámicas sociales, configuración de las relaciones familiares y las nuevas formas de violencia, sobrepasan el enfoque lineal y familista con el que opera el derecho en el trámite administrativo por violencia intrafamiliar. Las prácticas de re-victimización y violencia institucional, en el tratamiento del delito de violencia intrafamiliar, por medio de la reproducción de estereotipos de género, prácticas 
androcéntricas, conductas sexistas y misóginas, que discriminan y anulan la libertad de las mujeres, las comisarías de familia se enfrentan a retos importantes en la transformación cultural y frente a la preparación y capacitación de los profesionales que operan la justicia, en temas tales como los enfoques de género, enfoque diferencial y enfoque de derechos, los cuales den respuesta efectiva a las necesidades reales de las mujeres en los procesos jurídicos; como el proceso jurídico por sí solo no es reparador, se requiere de un ejercicio que interpele la subjetividad de la víctima por medio de ejercicios empáticos y solidarios.

Analizar las narrativas de las mujeres denunciantes de violencia, posibilitó comprender la relación entre la normalización del sistema patriarcal, con sus ideologías, estereotipos de género y normas sociales impuestas, con sus experiencias de denuncia de violencia ante esl sistema jurídico en sus localidades. Existen prejuicios y sesgos de género, sexismo y micromachismos en los operadores de justicia, en el procedimiento de recepción y tratamiento de las denuncias de las mujeres, constituyéndose en prácticas de revictimización y de violencia institucional de género hacia las víctimas que acuden en busca de protección, justicia y garantías de derechos.

Los relatos de las experiencias mujeres víctimas de violencia, evidenciaron que su percepción del trato que reciben dentro del sistema de justicia penal es fundamental para su voluntad de seguir participando en el proceso jurídico. Las investigaciones futuras podrían examinar una amplia gama de factores relacionados con el sistema como, por ejemplo, la duración del proceso, las acciones y el comportamiento de los jueces y juezas en las audiencias previas al juicio, y en qué medida los defensores y los fiscales permanecen en contacto con las víctimas. Finalmente, es importante resaltar que las consecuencias negativas, los daños morales y emocionales a las que se enfrentan las mujeres víctimas de violencia basada en género, no solo corresponden a las ejercidas por sus parejas o exparejas, las cuales son puestas en conocimiento por una intensificación o un periodo prolongado de tiempo, si no que enfrentarse a un sistema jurídico hostil y poco empático, genera un impacto devastador en el que de manera directa o indirecta reciben un mensaje de impunidad frente a hechos de violencia basadas en género.

\section{Referencias}

Abella, M. C., Ahumada, M. del P., Oviedo, M., Ramos, L. M., \& Torres P, K. (2017). La Violencia Intrafamiliar en Colombia, Leyes de Protección, Ruta de Atención y Motivaciones de Abandono del Proceso Judicial. Revista Navarra Jurídica, 1(1), 6-25. Recuperado a partir de https://journals.uninavarra.edu.co/index.php/navarrajuridica/article/view/a1-v1$\mathrm{n} 1-2017$ 
Achugar, H (1992). Historias paralelas/historias ejemplares: la historia y la voz del otro. Revista de Crítica Literaria Latinoamericana, 36, p. 51-73. https://doi.org/10.2307/4530622

Ashmore, R., \& Boca, F.K. (1979). Sex stereotypes and implicit personality theory: Toward a cognitive-Social psychological conceptualization. Sex Roles, 5, 219-248. https://doi.org/10.1007/BF00287932

Bennett, L., Goodman, L., \& Dutton, M. A. (1999). Systemic Obstacles to the Criminal Prosecution of a Battering Partner: A Victim Perspective. Journal of Interpersonal Violence, 14(7), 761-772. https://doi.org/10.1177/088626099014007006

Bodelón, E (2014). Violencia institucional y violencia de género. Anales de la Cátedra Francisco Suárez, 48, p.131-155. http://revistaseug.ugr.es/index.php/acfs/article/view/2783/2900

Bonino Méndez, L (2004). Micromachismos. Revista La Cibeles 2, 1-5. https://www.mpdl.org/sites/default/files/micromachismos.pdf

Botero, M (2020). Efectos psicológicos de la violencia en la relación de pareja, frente a la vida y autonomía de las mujeres. En. Serrano Ávila, Ana María (Comp.). (2020). Género y Derechos Humanos. Por la Salud y una Vida Libre de Violencias Derechos Humanos. p.167-192. Medellín, Colombia: Tecnológico de Antioquia - Secretaría de las Mujeres, Gobernación de Antioquia. https://www.researchgate.net/publication/340173627 Genero y Derechos Hu manos Por la Salud y una Vida Libre de Violencias Derechos Humanos

Congreso de la República de Colombia. (Julio 16 de 1996). Ley 294 de 1996, por la cual se desarrolla el artículo 42 de la Constitución Política y se dictan normas para prevenir, remediar y sancionar la violencia intrafamiliar. http://www.secretariasenado.gov.co/senado/basedoc/ley 0294 1996.html

Congreso de la República de Colombia. (Diciembre 4 de 2008). Ley 1257, por la cual se dictan normas de sensibilización, prevención y sanción de formas de violencia y discriminación contra las mujeres, , se reforman los Códigos Penal, de 
Revista Punto Género N.16 Diciembre de 2021

ISSN 2735-7473 / 169- 193

Procedimiento Penal, la Ley 294 de 1996 y se dictan otras disposiciones. http://www.secretariasenado.gov.co/senado/basedoc/ley 1257 2008.html

Corte Constitucional de Colombia (2017). Sentencia T-735. http://www.corteconstitucional.gov.co/relatoria/2017/t-735-17.htm

Corte Constitucional de Colombia (2017). Sentencia T-338. http://www.corteconstitucional.gov.co/relatoria/2018/t-338-18.htm

Díaz Alzate, M. V., Durán Palacio, N. M., y Gómez Durán, D. (2021). Sobre la lucha de Ser Mujeres: subjetividades políticas femeninas. The Qualitative Report, 26(10), 3171-3188. https://doi.org/10.46743/2160-3715/2021.4922

Fenton, Z. E. (1998). Domestic Violence in Black and White: Racialized Gender Stereotypes in Gender Violence. University of Miami. http://dx.doi.org/10.2139/ssrn.137037

Finkelhor, D., Ormrod, R., \& Turner, H (2007). Poly-victimization: A neglected component in child victimization. Child Abuse \& Neglect, 31(1), p.726. http://dx.doi.org/10.1016/j.chiabu.2006.06.008

Gadamer, HG. (1984). Verdad y método: fundamentos de una hermenéutica filosófica. Sígueme: Salamanca.

Glaser, B \& Strauss, A. (1967). The discovery of grounded theory: strategies for qualitative research. Hawthorne, N.Y.: Aldine de Gruyter.

Glaser, B (1992). Basics of grounded theory analysis. California: Sociology Press.

Herrera Paredes, J. M., \& Ventura, C.A (2010). Consumo de alcohol y violencia doméstica contra las mujeres: un estudio con estudiantes universitarias de México. Revista Latino-Americana de Enfermagem, 18(spe), p.557-564. https://doi.org/10.1590/S0104-11692010000700011 
Hester, M. (2014). A través del sistema penal: la experiencia de las mujeres en Inglaterra. En: Bodelón, Encarna. (Ed.). (2014). Violencia de género y las respuestas de los sistemas penales. p.235-269) Barcelona, España: Didot.

Martínez Miguelez, M (2004). La ciencia y el arte en la investigación cualitativa. México: Trillas.

Ministerio de Justicia y del Derecho (2012). Justicia y Género. II Lineamientos técnicos en violencias basadas en género para las Comisarías de Familia. Bogotá, Colombia: Ministerio de Justicia y del Derecho. https://colectivajusticiamujer.org/product/lineamientos-tecnicos-en-violenciasbasadas-en-genero-para-las-comisarias-de-familia/

Naciones Unidas. Oficina del Alto Comisionado para los Derechos Humanos (1993). Declaración sobre la eliminación de la violencia contra la mujer. https://www.ohchr.org/sp/professionalinterest/pages/violenceagainstwomen.as $\underline{\mathrm{px}}$

Naredo, M., Casas, G.,\& Bodelón, E (2014). La utilización del sistema de justicia penal por parte de mujeres que enfrentan la violencia de género en España. En: Bodelón, Encarna. (Ed.) (2014). Violencia de género y las respuestas de los sistemas penales. p. 27-104. Barcelona, España: Didot.

Organización de las Naciones Unidas- ONU-. (2019). Global study on homicide. https://www.unodc.org/documents/data-and-analysis/gsh/Booklet 5.pdf

Organización de los Estados Americanos -OEA- (1994). Convención de Belém do Pará. https://www.oas.org/es/mesecvi/convencion.asp

Palacio Valencia, M.C (2008). La pregunta por las Masculinidades Otra arista en la construcción de la inclusión sin discriminación y la equidad participativa en las familias contemporáneas. Centro Bartolomé de las Casas. http://www.lazoblanco.org/wpcontent/uploads/2013/08manual/bibliog/material masculinidades 0454.pdf?49 $\underline{\text { cf } 6 f \& 49 c f 6 f}$ 
Parsons, T. (1978) La estructura social de la familia. En: E. Fromm, M. Horkheimer, T. Parsons (eds.) La familia. (pp. 31-66). Península.

Peña, L (2018). La relación entre los celos de pareja y la violencia intrafamiliar en madres de familia de una institución educativa de san juan de Lurigancho, Lima-Perú (Tesis de pregrado Licenciatura en Psicología). Universidad Cesar Vallejo. Lima-Perú. https://repositorio.ucv.edu.pe/handle/20.500.12692/23776

Portal de Salud de Murcia (2010). Guía práctica clínica. Actuación en salud mental con mujeres maltratadas por sus parejas. Murcia, España: Servicio Murciano de Salud. https://portal.guiasalud.es/wpcontent/uploads/2018/12/GPC 470 maltratadas compl.pdf

Puyana Villamizar, Y (2019). El familismo, sus fuentes y su articulación con la legislación $\begin{array}{llll}\text { colombiana. Revista } & \text { Palobra. } & \text { 19(1), } & \text { 42-61. }\end{array}$ https://revistas.unicartagena.edu.co/index.php/ alabra/article/view/2466/2068

República de Colombia. (1991). Constitución Política de Colombia. Capítulo 2. Art. 42. http://www.secretariasenado.gov.co/index.php/constitucion-politica

Saldarriaga, D.,, Ariza, G.,, Cano, B., \& Saldarriaga, L (2020). Violencias huérfanas: vacíos jurídicos de la violencia jurídica. En: Género y Derechos Humanos. Por la Salud y una Vida Libre de Violencias Derechos Humanos. (pp. 167-192). Medellín, Colombia. Disponible en: https://www.researchgate.net/publication/340173627 Genero y Derechos Hu manos Por la Salud y una Vida Libre de Violencias Derechos Humanos

Segato, R. L (2003Las estructuras elementales de la violencia: ensayos sobre género entre la antropología, el psicoanálisis y los derechos humanos.. Buenos Aires, Argentina.: Universidad Nacional de Quilmes.

Segato, R. L (2012). Femigenocidio y feminicidio: una propuesta de tipificación. Revista Herramienta,

Disponible en: https://biblat.unam.mx/hevila/HerramientaBuenosAires/2012/no49/10.pdf

Segato, R L (2018). Contra-pedagogías de la crueldad. Buenos Aires, Argentina: 
Revista Punto Género N.16 Diciembre de 2021

ISSN 2735-7473 / 169- 193

Prometeo.

Serrano Gallardo, P (2012). La perspectiva de género como una apertura conceptual y metodológica en salud pública. Revista Cubana de Salud Pública, 38(Supl. 5), 811-822. $\quad$ http://scielo.sld.cu/scielo.php?script=sci arttext\&pid=S086434662012000500014\&lng=es\&tlng=es.

Sparkes, A \& Devís, J. (2008). Investigación narrativa y sus formas de análisis: una visión desde la educación física y el deporte. En: Moreno, William (Ed.). Educación cuerpo y ciudad: El cuerpo en las interacciones e instituciones sociales. Medellín: Funámbulos Editores. p. 43-68.

Strauss, A. \& C, J (2002). Bases de la investigación cualitativa: técnicas y procedimientos para desarrollar la teoría fundada. Medellín: Editorial Universidad de Antioquia.

Vásquez, Machado A (2007). Relación entre violencia y depresión en mujeres. Revista de Neuro-Psiquiatría, 70(1-4), p.88-95. https://www.redalyc.org/pdf/3720/372039390004.pdf 